\title{
Capitalist and Communal Foundations in The Bingo Palace
}

Kelsey Rolofson is a senior majoring in English and Political Science. She is from Wildwood, Missouri. This article was supervised by Dr. Dorice Elliott.

Abstract:

Published in 1994, Louise Erdrich's novel The Bingo Palace traces the journey of Lipsha Morrissey, who is called by his grandmother to return to his childhood home, a fictional Ojibwe reservation, after years of living off-reservation with his father. Upon his return, Lipsha becomes enamored with a young woman, Shawnee Ray Toose, and entangled in conflict with Lyman Lamartine, Lipsha's uncle, half-brother, and the father of Shawnee Ray's child, who plans to build a glamorous "Bingo Palace" on reservation land to bring wealth to the Ojibwe people. As Lipsha struggles to reconcile his multi-layered conflict with Lyman, he faces questions of identity, family, and an ethical dilemma: would the economic benefits of a "Bingo Palace" outweigh the cultural costs? This paper examines the seemingly contradictory issues that arise in the novel regarding the titular Bingo Palace, Native gaming and gambling traditions, and the American capitalist superstructure through an analysis of the complex relationship between Lipsha and Lyman.

Literature Review:

Scholarly and literary criticism of Erdrich's The Bingo Palace largely focuses on Lipsha's struggle with Western ideology and how Indigenous definitions of home, family, and identity are complicated and influenced by the forces of colonialism and capitalism in modern America. The novel's account of the rise of Native American gaming following the Indian Gaming Regulatory Act of 1988 has garnered critical acclaim, while literary critics make note of Erdrich's stylistic technique, which combines Ojibwe cultural elements with historical and fictionalized events, and the novel's thematic commentary on Ojibwe identity and familial relationships. This paper specifically examines the relationship between Lipsha and Lyman as representative of the central conflict of the novel, necessarily nested within Erdrich's examination of Native gaming practices, casino gambling, family, and identity.

T ouise Erdrich's novel The Bingo

1 Palace centers on the tension between two inverse ideologies: American capitalism and traditional Native communalism. This conflict is illustrated by the differing ideals of main characters Lyman Lamartine and Lipsha Morrissey and the proposed development of a reservation gambling institution, the titular "Bingo Palace," on Ojibwe land. Lipsha, who has lived off-reservation for some time, returns to the reservation to connect with his family and the Ojibwe community. Although Lipsha has been directly influenced by the lifestyle of American capitalism, he decides to honor his spiritual connection to his family by returning home. This internal tension, in which Lipsha feels like an outsider both as a Native person in Western society and an alien to his home, leads Lipsha to a vision quest, where he is 
confronted not only by symbols of Western materialism, but also by his ancestor, the history of ancestral lands, and a skunk's mantra-like sentiment: "This ain't real estate" (Bingo 200). Meanwhile, Lyman's pursuit of a reservation casino, which begins as a communal project that could bring economic stability and prosperity to the Ojibwe community, becomes corrupted by his individual interests: his penchant for gambling and his drive for financial success and power. As Lyman becomes more invested in his capitalist venture, he devalues his investment in his people and even his own familial connections.

Although Lyman and Lipsha seem to be ideological opposites, they are connected through their family tree, the larger Ojibwe community, their love for Shawnee Ray, and the Bingo Palace. Lipsha comes to realize that the casino cannot merely be a place for economic return, nor just a symbol of money or the culture of Western capitalism but should be an important site for cultural affirmation and the honoring of Ojibwe people and traditions. Although the novel ends before the casino is built, through Lipsha and Lyman's conflict, which is represented both in their differing ideological perspectives and their competing romantic interests in Shawnee Ray, and the influence of both Native traditions and Western capitalism on each of them, Erdrich illustrates the possibility of a Bingo Palace that is founded in an appreciation of culture and community, not simply the aggregation of individual wealth. Thus, the rags-to-riches narrative in The Bingo Palace operates on several levels: while the casino could secure economic capital for individuals and the tribe as a whole, that capital must be shielded from the corrupting forces of Euro-American capitalism by the enrichment of a generational, familial, spiritual connection to the community and ancestry, a constant commitment to that communal foundation, and a cultural appreciation of Ojibwe traditions that does not sink into stereotypical, monolithic portrayals of Native communities.

In The Bingo Palace, gambling represents both a modernized Native tradition and the necessary yet corrupting forces of capitalism. Erdrich, herself a member of the Turtle Mountain Band of Ojibwe (Kurup 223), envisions the development of a reservation casino on Ojibwe land along with "the accompanying concerns over the preservation of tribal culture" (224). While the novel recognizes the economic benefit the Bingo Palace could bring, The Bingo Palace is most concerned with the cultural costs of choosing "economic security at the expense of cultural distinctiveness" (Kurup 224). The novel's concern with the concept of the reservation casino demands an acknowledgement of the particularities of American racism and classism and the colonial legacies that play into the perception, legal treatment, and social environment surrounding reservation casinos. The Bingo Palace explores the cultural effects of contemporary capitalism on Native American communities but refuses to conform to the "typical Western binary" that economic stability is not achievable for Native Americans without damaging cultural identity (Kurup 225). Along the way, The Bingo Palace highlights controversy among contemporary Native communities about traditional Indigenous gaming versus corporatized gaming practices. 
Some scholars argue that Erdrich's novels reveal that gambling can be compatible with some tribes' values as a "'natural by-product of the tribal system"' (Kurup 227), whereas other scholars view traditional tribal wagers as substantially different than corporate or capitalist gambling. Kurup quotes literary scholar Paul Pasquaretta's analysis of the discrete qualities of Native American versus Western gaming practices, in which Pasquaretta argues that, "Unlike Euro-American games of chance, which function as secular rituals and foster acquisitiveness, individual competition, and greed, traditional Native American games of chance are sacred rituals that foster personal sacrifice, group competition and generosity" (227). Because Indigenous gaming traditions were developed within a classless society, individuals participated in hopes of securing winnings for the common benefit and to restore balance to a tribe or between conflicting tribes. Gambling losses and gains were not tools for individual wealth aggregation, but were instead comprised of communal resources, so games of luck and chance contributed to the fair distribution of those resources among members of the community (227). Thus, gambling emerges from Erdrich's body of literature as "a strategy for tribes to recapture what has been lost to European traders, settlers, and the United States government. Gambling presents a means by which, in the absence of an equitable legal apparatus, tribes can counter the devastating losses of colonialism" (Kurup 230-231). Indeed, reservation casinos were legally implemented not just to support Indigenous tribes' quest for economic stability, but as a recognition of tribal sovereignty (Cramer 314). The Bingo Palace was published shortly after the introduction of the Indian Gaming Regulatory Act (IGRA) and other regulatory measures into federal law in 1988. These changes federally legalized the reservation casino and determined protocols for tribal sovereignty that could allow tribes to enter into agreements with the government (Cramer 314). Therefore, The Bingo Palace acts as a historical response to the rise of the reservation casino and imagines the complications of an institution that represents tribal sovereignty in internal and economic affairs, which in some ways resists capitalism. Yet the reservation casino must play into capitalist ideology and cater to non-natives to be successful, which entrenches the casino in capitalist venture, despite its supposed sovereignty. However, if the casino is run by and for the Ojibwe, is it a net benefit despite the cultural cost?

While the reservation casino in The Bingo Palace offers both advantages and risks for the tribe, Erdrich seems particularly concerned with the cultural repercussions of the bingo as "a typically Western capitalist method of wealth accumulation designed to benefit individuals rather than communities" (Kurup 230). Lipsha recognizes that the casino could ensure the tribe stays alive (Bingo 221), and if the reservation casino could ensure the tribe's survival, it would therefore preserve their cultural identity. However, the Bingo Palace could ultimately destroy the culture it was intended to protect by "enacting this paradigm of capitalism on the reservation," which may result in a general assimilation (Kurup 231). The Lipsha and Lyman rivalry portrays this paradox, representing the "internal struggle to bal- 
ance the communal spirit of the tribe with its capitalist aspirations" (231). While the entrepreneurial Lyman pioneers the Bingo Palace project, and Lipsha seems more uneasy about the use of Ojibwe land for such a venture, both characters ruminate on the consequences of cultural sacrifices that may be traded for the promise of economic stability. An analysis of reservation casino culture can illuminate precisely how these institutions can succumb to the pitfalls of capitalism, define and honor their cultural identity, or fall somewhere in between.

As reservation casinos have become more ubiquitous since the passage of IGRA, their potential for fiscal success and cultural demolition is evident. To explore the portrayal of Native public identity, defined as a tribe's "articulations of collective world views, experiences, and practices" (Lawlor 31), scholar Mary Lawlor traveled to significant cultural sites of four Indigenous communities that interface with largely non-Native audiences. Lawlor reports on two commercial casinos, Foxwoods Resort Casino and Sky City Casino, which are both financially successful tribal enterprises yet offer different portrayals of the tribes that sponsor them. Foxwoods, the largest casino in the United States, is owned and operated by the Mashantucket Pequot tribe and has brought significant economic prosperity to their community (31). In conjunction with the adjacent Mashantucket Pequot Museum and Research Center, Foxwoods functions as a vehicle of "intentional as well as inadvertent public rhetoric" through which the Pequot tribe, like many others, communicates Pequot cultural identity for the non-Native audience visiting the casino (31). But Law- lor argues that, as a result of the capitalist culture of the reservation casino, Pequot public identity has been "renegotiated" to emphasize the tribe's connection to a more national, even global, economic and social environment (31). Lawlor cites the decorative elements of Foxwoods that "project a certain 'Indian' ambience," not for authentic representation of the culture, but to evoke a recreational gambling environment (133). However, Lawlor posits that, in conjunction with the Museum and Research Center, Foxwoods does attempt to frame the casino experience within a tradition of authentic Native gaming. Sky City Casino, on the other hand, boasts a forty-foot tall blinking neon sign and a casino environment that "promises no lessons or information about the tribe at all" (133), but instead functions solely to make money for the Acoma Pueblo tribal nation.

The grandeur of Sky City Casino is reminiscent of the allure of the Sands Regency casino in Las Vegas, in which Lyman becomes ensnared when he visits for the Indian Gaming Conference. The Sands Regency is explicitly a material, capitalist venture. By virtue of its sheer size, dizzying opulence, and incorporation of name brands at every corner, from Orange Julius to Obsession (Bingo 90), everything is corporate-coded for the purpose of money-making. At first, Lyman is awestruck by this environment and has a series of lucky wins; the chips accumulate and he eventually cashes in, eating and drinking himself to sleep in a gluttonous binge. He wakes in the middle of the night, hungry for more luck, and although he has a winning streak at first, he begins to win less and less often. As his luck starts 
to dwindle, a dark feeling washes over him, "a low wave, a green slide of nausea," after which he "told himself to leave" (93). But he cannot pull himself away, as his rational mind and hunger for more "split" him into two people. After his luck turns, he loses his way, becomes desperate. Lyman continues to play "for the nostalgia of feeling the luck, wanting it to return, as much for the money," until he loses everything he had won and more (93). In this scene, Erdrich ties the pursuit of economic capital and the dizzying casino environment intimately with the pursuit of luck, demonstrating the appeal and drawbacks of casino culture, the unpredictability of the game, the highs of the wins and the lows of the losses. Lyman's experience displays this never-ending cycle that breeds destructive behaviors, obsession, and addiction, which in turn perpetuate the influx of capital into the casino. When Lyman is immersed in this environment, he is amazed not only by the draw of gambling but also the sights and sounds of the casino and the corporate gleam. As a result of this environment plus the incessant pull of the game, Lyman cashes in the money entrusted to him for the benefit of the tribe, and sells a ceremonial pipe, with which he previously had a meaningful spiritual, communal, and ancestral connection (87). He betrays his dream, his community, and his own history because he is "completely immersed in the pleasure of playing" (Quennet 205), which seems to suggest that the traditions and cultural symbols of a Native American lifestyle cannot survive in mainstream American culture. The representation of the classic, corporate casino in The Bingo Palace emphasizes the possible cost of the tribal pursuit of economic success, perhaps at the expense of communal values and the "commodification of tribal traditions, symbols, and cultural artifacts" (Kurup 225). Therefore, in the chapter "Lyman's Luck," Lyman embodies the hazards of the casino environment, particularly when that enterprise is based in capitalist interests.

Despite Erdrich's illustration of the cultural risks of a reservation casino, The Bingo Palace does not submit to the imposed binary of Western capitalist versus Native communal values. The intertwining journeys of Lipsha and Lyman demonstrate the complex relationship between these two economic ideologies within Ojibwe culture. Lipsha's approach to the Bingo Palace problem and the notion of the reservation casino is influenced not only by his connection to Western culture but also his spiritual connection to the Ojibwe land and people. At the beginning of the novel, Lipsha is an outcast from the community, as a result of his father's delinquent behavior and his own departure from the reservation to do manual labor harvesting sugar beets. The community claims that Lipsha is "destined" to become "one of those sad reservation statistics" (Bingo 7), but perhaps because of his separation from the community, Lipsha is "destined to become another statistic of Western ideology" (Wilson 47). Upon returning to the reservation, Lipsha has lost some of his innate power; although "his touch was strong" as a descendent of healer and matriarch Fleur Pillager, "he shorted it out" and was "weakened and confused" by going back and forth to the city (Bingo 8). The tribe believes that Lipsha doesn't "fit" any longer (Bingo 9), and as a result, 
he is caught between his Ojibwe self-identity, with which he is spiritually connected yet socially alienated, and "what Western encroachment influences him to become" (Wilson 47). Lipsha's relationship to the reservation is further influenced by his personal trauma, particularly his mother's attempt to drown him as an infant. His dreams of love are "tied up with his trauma" (Harper 26) and his character, marked by his obsessive and impulsive behaviors, reflects a desire for both a "transformed self and community" (23-24). Lipsha's quest to come to terms with his identity as an individual, a member of his family, and his Ojibwe community are tied to his trauma and, ultimately, his spiritual quest.

Lipsha also has a spiritual, ancestral connection to the game of bingo, which emerges when his mother's spirit appears to him, telling him to play bingo and providing him with lucky numbers. Bingo and other Native games of chance serve to blur the boundary between "one reality and another," meaning the spiritual and human realms (Quennet 212), and Lipsha sees the intersection of these during his vision quest. As his journey progresses, Lipsha begins to see visions that he thinks are wrong or inconsistent with the traditional notion of a vision. He sees "clouds raining money into the open mouths of the tribal bank accounts" (Bingo 219) and a casino dome as the shape of a great stone turtle (220); this leads him to realize the connection between gambling and Ojibwe traditions (Quennet 205). Ultimately, Lipsha is visited by a skunk, who repeats, "This ain't real estate." The phrase seems to point to the plans to build a Bingo Palace on tribal land, but, somewhat strangely, "the plans for land development originate within his tribe, in fact within his own family" (Kurup 223). While enterprising tribal leaders like Lyman have adopted the values of capitalism, entrepreneurship, and individualism, they "rarely consider the effect of gaming on tribal sovereignty or the cultural cost involved in this financial venture" (223). On the other hand, after Lipsha experiences these visions, he ruminates on the cycle of gambling and concerns about the Bingo Palace, wondering "if we're going in the wrong direction, arms flung wide, too eager," and claiming that "Money gets money, but little else, nothing sensible to look at or touch or feel in yourself down to your bones" (Bingo 221). Lipsha's concerns about the Bingo Palace are rooted in a deep connection to his spiritual concerns, and he ultimately agrees with the skunk that "our reservation is not real estate, luck fades when sold" (221). In this moment, Lipsha depicts the bingo as a site of soulless attraction, yet he recognizes that it is intimately tied to Ojibwe tribal concerns, people, and culture.

Lipsha and Lyman's contrasting ideological perspectives heighten the tension between capitalist ventures and communal well-being in the novel. Lyman is less attuned to the cultural concerns that Lipsha mulls over, but instead of pursuing the bingo entirely for his own interests, he believes that a casino on ancestral land might be, in fact, a net communal good. In a dream, Lyman's grandmother, Fleur, tells Lyman that "Land is the only thing that lasts life to life. Money burns like tinder, flows off like water, and as for the government's promises, the wind is steadier" (Bingo 148), which seems aligned with Lipsha's concerns. However, 
she further explains that Lyman's pursuit of the casino could secure a communal good and an ancestral legacy: "Put your winnings and earnings in a land-acquiring account. Take the quick new money. Use it to purchase the fast old ground" (Bingo 149). After this vision from Fleur, Lyman envisions his Bingo Palace venture unfolding into a prosperous life for his family and the land.

Furthermore, Lyman's faith in his own luck reflects Native traditions of trust in luck and chance, which can lead to "power[,] survival" (Quennet 208), and spiritual experience. The tradition of gambling, for many Indigenous cultures, is "rooted in religious rites and festivals," a sacred experience (Quennet 208). Indeed, even the Sky City Casino is an important ceremonial site to which many members of the Acoma Pueblo regularly return (Lawlor 135). Casinos like Sky City and the titular Bingo Palace can generate the economic resources that could help buy back land, as in the case of the Acoma Pueblo (Lawlor 134) and provide tribes with the power to reaffirm their tribal sovereignty (Cramer 321). Thus, for many Indigenous communities, the tradition of Native gambling is rooted in cultural significance, and the capitalist forces that drive the casino enterprise can be used to benefit the community. In The Bingo Palace, Lyman's interest in the casino is bound to his concerns for the wellbeing of his family and community and, although he differs from Lipsha in his approach to the Bingo Palace, they actually share a common goal: the preservation of the Ojibwe people, land, and culture.

These two characters' differing yet coexisting ideological perspectives complicate the distinction between them because both Lyman and Lipsha are deeply influenced by the "social, economic, and cultural forces of Native communalism and American capitalism, neither of which can fully encompass the characters' existences alone" (Wilson 42). Erdrich does not perpetrate the "monolithic dichotomies" often drawn between Native and Euro-American worldviews, but instead "celebrates the interdependence of this dual cultural contact" (Quennet 217). Lipsha and Lyman's rivalry and conflicting concerns are resolved through Lipsha's realization that he can essentially "balance out Lyman's desires by ensuring that the land is not irretrievably corrupted" (Kurup 239) by making certain that cultural preservation is at the heart of the Bingo Palace rather than economic gain. Lipsha understands that money has "no substance" and "is not based on solid ground" (Bingo 221), but the Ojibwe history, land, and people are. Considering this, Lipsha concludes that "it's not completely one way or another, traditional against the bingo. You have to stay alive to keep your tradition alive and working" (221). As long as the casino fulfills this aim of cultural preservation, which Lipsha sees as its core purpose, he will not stand in its way. Erdrich's presentation of Lipsha as spiritual and Lyman as material ultimately serves the purpose of blending these perspectives because both are touched by Western capitalism and Ojibwe tradition, proving that each ethos is "necessary for the success of the reservation casino and the future of the tribe" (Kurup 233). Ultimately, both Lipsha and Lyman understand that tribal values can be preserved through the pursuit of reservation gambling, so long as 
the casino remains aligned with Ojibwe traditions, culture, history, and the well-being of the community.

The Bingo Palace endeavors to reconcile Native American culture and customs that exist within a capitalist, colonial world. Through the symbiotic relationship between Lipsha and Lyman, the novel proposes a resolution in which the Ojibwe "meld tribal values with practical economic solutions" (Kurup 231). In order to secure their land and their future, Native American communities must pursue reservation gambling in the spirit of tribal values rather than solely for the purpose of economic prosperity. If the casino is founded and maintained on the basis of cultural preservation, rather than purely for the sake of capital, which can produce negative portrayals of Native gambling traditions, then the economic benefit would not cost cultural identity but would ensure its endurance. Ultimately, the capitalist versus communitarian conflict is a paradox in itself: the community cannot survive without playing into the capitalist system, yet it cannot truly survive by betraying its values to conform to the expectations of that system. While the novel ends before the effects of this conflict play out, the struggle to solidify the intention for the reservation casino and the quality of the culture that it affects ultimately results in an affirmation of Ojibwe cultural identity. 


\section{Works Cited}

Cramer, Renee Ann. “The Common Sense of Anti-Indian Racism: Reactions to Mashantucket Pequot Success in Gaming and Acknowledgment." Law \& Social Inquiry, vol. 31, no. 2, Spring 2006, pp. 313-341.

Erdrich, Louise. The Bingo Palace. HarperCollins, 1994.

Harper, Mary Catherine. "Figuring the Grotesque in Louise Erdrich's Novels: Of Ojibwe Play, Modernist Form, and the Romantic Sensibility." Studies in American Indian Literatures, vol. 24, no. 2, Summer 2012, pp. 17-38.

Kurup, Seema. "Rolling the Dice: The Rise of the Reservation Casino and the Native American Fight for Cultural Survival." All In: The Spread of Gambling in Twentieth-Century United States, edited by Jonathan D Cohen and David G Schwartz, University of Nevada Press, 2018, pp. 151-166.

Lawlor, Mary. Public Native America: Tribal Self-Representation in Casinos, Museums, and Powwows, Rutgers University Press, 2006.

Quennet, Fabienne C. "Where 'Indians' Fear to Tread?: A Postmodern Reading of Louise Erdrich's North Dakota Quarter." Studies on the History, Politics, and Society of North America, vol. 18, 2001.

Wilson, Jonathan. "Old Wives, the Same Man, and a Baby: Location and Family as the Foundation of Home in Tales of Burning Love and Bingo Palace." Studies in American Indian Literatures, vol. 24, no. 1, Spring 2012, pp. 31-61. 